\title{
FIBRE LASER WELDING FOR LIGHTWEIGHT DESIGN
}

\author{
Paper \# P128
}

\author{
Jan Karlsson ${ }^{1}$, Alexander Kaplan ${ }^{1}$ \\ ${ }^{1}$ Luleå University of Technology, SE-971 87 Luleå, Sweden; www.Itu.se/tfm/produktion
}

\begin{abstract}
Two different high strength steel grades have been welded by a fibre laser to create a fillet corner joint. The purpose of this experiment is to use thinner materials of higher strength as a weight reduction strategy. The sensitivity of the welding process to the beam inclination angle, the beam position and the focal plane position were studied. High-speed imaging, process emission monitoring, measurement of the weld surface topography, mechanical testing and FEanalysis have been used to analyse the process and the resulting weld. A combined study by these methods gives a more comprehensive picture for studying the weld quality. A Bifurcation Flow Chart (BFC) has been applied as a new method to standardise and generalise the findings.
\end{abstract}

Keywords: laser, welding, lightweight, high strength steel, fibre

\section{Introduction}

Knowledge management from experimental and theoretical findings in the field of laser materials processing is addressed in the present paper. The project behind this research and evaluation is called LOST (Lightweight Optimization of conSTructions), focussing on weight reduction in different automotive construction applications. Savings in construction costs and fuel consumption can be made by reducing weight. When reducing weight, weld design can have a key role, particularly by enabling the change to high strength steel. Using laser welding reduces the heat affected zone (HAZ) to a very narrow zone which hardly affects the mechanical properties of the weld and the product under load, as compared to traditional arc and spot welding methods.

This project aims at weight reduction by laser welding of high strength steel for certain applications, and at the same time aims at initiating a knowledge platform for lightweight structures, including, besides other issues, the optimization of welding technology.

\section{Knowledge platform}

Laser welding is known for its many advantages over more traditional technologies, but suffers from difficulties in controlling the process quality, as it is a complex and not fully understood process. Various welding defects that can occur have to be minimised to achieve a quality that satisfies the loading conditions of welded products in service. The new high brilliance lasers (fibre, disc) can - due to their excellent beam properties - give improved welding performance, but this can be at the expense of more pronounced violent evaporation and spatter, which needs to be eliminated [1]. Some reviews $[2,3]$ survey the monitoring of welding defects [4] by either cameras or photodiodes. A few research groups have applied advanced methods like Finite Element Analysis (FEA) [5] or high speed imaging $[1,6,7]$ for analysis and even combine them e.g. FEA and imaging [5], X-ray imaging of pore formation followed by modelling [7] or photodiode monitoring and high speed imaging combined with modelling $[6,8]$.

An approach to combine data and knowledge from different methods in order to provide a comprehensive picture on the process and resulting welded product is under development [9]. One method to illustrate, generalize and standardise the documentation of findings is the Bifurcation Flow Chart (BFC) [10].

In Tab. 1 a number of defects that might occur during laser welding of metals are represented in an adapted version of the Swedish standard SS-EN ISO 13919-1 [11]. The table explains defects and probable causes for them. They are used in experiments to classify weld defects. Together with the BFC, rules and statements on how to avoid a certain defect in a certain situation can be stated. 
Table. 1: Different types of defects occurring during laser welding

\begin{tabular}{|c|c|c|}
\hline Defect & & Explanation \\
\hline 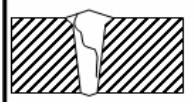 & Cracks & $\begin{array}{l}\text { Hot crack in the fusion zone or } \\
\text { cold in HAZ }\end{array}$ \\
\hline & $\begin{array}{l}\text { Porosity and } \\
\text { gas pores }\end{array}$ & $\begin{array}{l}\text { Voids in the material } \\
\text { Spherical = gas bubbles } \\
\text { Irregular = impurities }\end{array}$ \\
\hline & $\begin{array}{l}\text { Incomplete } \\
\text { penetration }\end{array}$ & $\begin{array}{l}\text { Not deep enough } \\
\text { penetration }\end{array}$ \\
\hline & $\begin{array}{l}\text { Linear } \\
\text { misalignment }\end{array}$ & $\begin{array}{l}\text { The two parts centerlines do } \\
\text { not coincide }\end{array}$ \\
\hline & $\begin{array}{l}\text { Lack of } \\
\text { fusion }\end{array}$ & $\begin{array}{l}\text { The two parts are not welded } \\
\text { throughout the entire weldzone }\end{array}$ \\
\hline 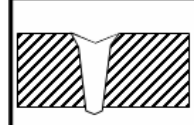 & $\begin{array}{l}\text { Undercut } \\
\text { Root sagging }\end{array}$ & $\begin{array}{l}\text { Lack of material in upper } \\
\text { weldzone } \\
\text { Too much material in lower } \\
\text { weldzone }\end{array}$ \\
\hline Olle & $\begin{array}{l}\text { Reinforcement } \\
\text { Root cavity }\end{array}$ & $\begin{array}{l}\text { Too much material in upper } \\
\text { weldzone } \\
\text { Not enough material in lower } \\
\text { weldzone }\end{array}$ \\
\hline & Blowout & Crater formation on top surface \\
\hline
\end{tabular}

To enable welding information to be transferred and used in a larger perspective, creating a broad knowledge platform may be a solution. A problem with most studies today is that the information presented by them is not directly transferable to different applications, although the same solutions for suppressing defects might be applicable. By producing a broad knowledge platform from a weld situation (even if not all is usable) other similar, but different, applications may use parts of it to facilitate an increase the weld quality [9].

\section{Method}

When building a knowledge platform, a wide spectrum of methods can be applied to analyze the welding process and its result, ultimately linking them together by conclusions and making generalizations. Intermittent sampling and analysis are the main steps when analysing welding in the present project, as listed in Tab. 2. By comparing different methods, more comprehensive information is obtained and a better understanding of defects may be achieved.
Table. 2: Platform of analysis methods applied

\begin{tabular}{l|l|}
\hline Analysis & Method \\
\hline $\begin{array}{l}\text { Visual } \\
\text { analysis }\end{array}$ & $\begin{array}{l}\text { Inspection of top and root geometry } \\
\text { Metallurgy, microscopy and } \\
\text { inspection of the weld cross section } \\
\text { geometry }\end{array}$ \\
\hline $\begin{array}{l}\text { Non-visual } \\
\text { analysis }\end{array}$ & $\begin{array}{l}\text { Hardness test of the weld cross } \\
\text { section geometry } \\
\text { Mechanical testing }\end{array}$ \\
\hline $\begin{array}{l}\text { Numerical } \\
\text { simulation }\end{array}$ & $\begin{array}{l}\text { Finite Element Analysis (FEA) of the } \\
\text { stress field in the welded joint under } \\
\text { load conditions }\end{array}$ \\
\hline $\begin{array}{l}\text { Intermittent } \\
\text { imaging }\end{array}$ & $\begin{array}{l}\text { High speed imaging of the weld zone } \\
\text { with }{ }^{\dagger} \text { and without laser illumination }\end{array}$ \\
$\begin{array}{l}\text { Photodiode monitoring system with } \\
\text { three simultaneous spectrally filtered } \\
\text { sensors for } \\
\bullet \quad 1070 \text { nm (beam reflection) } \\
400-600 \text { nm ("plasma" sensor) } \\
1100-1200 \text { nm ("temperature" } \\
\text { sensor) }\end{array}$ \\
\hline $\begin{array}{l}\text { Generaliza- } \\
\text { tion of rules }\end{array}$ & $\begin{array}{l}\text { Illustrative theory } \\
\text { Bifurcation Flow Chart (BFC) }\end{array}$ \\
\hline \begin{tabular}{l} 
Used for analysis in the present paper \\
\hline
\end{tabular}
\end{tabular}

The above methods have been applied in various combinations recently. Examples are given in the following, while the marked methods are used in the present study.

\section{Photodiode monitoring analysis}

A photodiode monitoring system has been used together with inspection of top and root geometry, inspection of cross section geometry and high speed imaging to successfully identify undercut, making detection by photodiode monitoring in real-time possible, Fig. 1 [8]. The figure shows a signal that is below the set lower limit of the monitoring signal range of acceptance. 


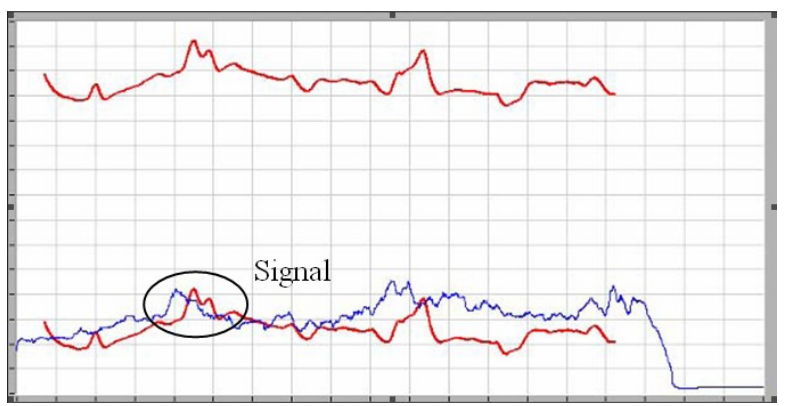

Figure 1. Photodiode (Plasma) sensor signal voltage $U(t)$ (blue) and threshold range (red), here for undercut detection [8].

\section{Finite Element Analysis}

Finite Element Analysis (FEA) has been used to calculate the stress field of the weld under load [12]. Fig. 2 shows the cross section for a weld similar to the one presented and analyzed later in the paper, but produced by laser hybrid-welding. In Fig. 2a (for bending load) stress raisers can be seen in the toes that are dependent on the curvature and which are critical for crack initiation. For this reason sharp corners or undercut should be avoided. Fig. $2 b$ shows a measurement of the weld surface topography and the induced peaks in the simulated stress field can be seen in Fig. 2c.

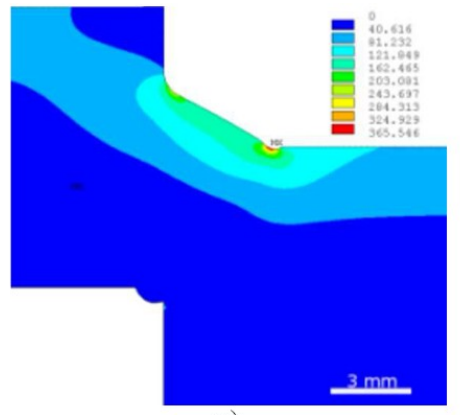

a)

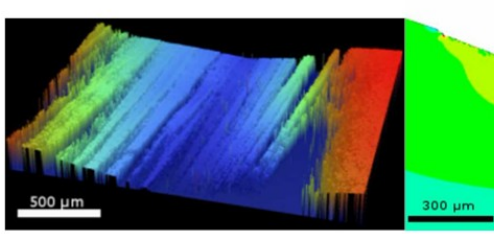

b)

Figure 2. a) first principal stress field of the weld cross section during bending, b) weld surface topography, c) its calculated impact on the stress field

\section{Mechanical testing}

Fatigue testing for the same joint [12] resulted in cracking as in Fig. 3a, in good agreement with crack propagation FE-simulation, see Fig. 3b. The analysis also explained why the lack of fusion in the center of the weld was not critical in this case.

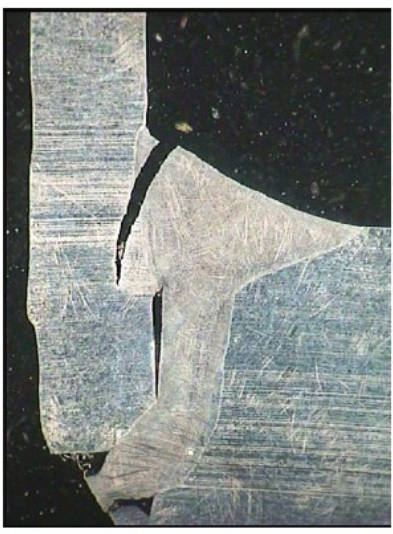

a)

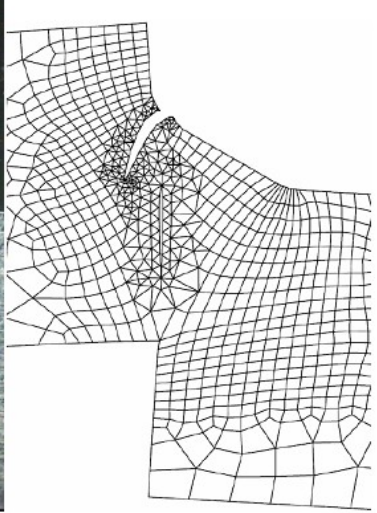

b)
Figure 3. Weld cross section with crack initiation a) after fatigue testing, b) from FE-analysis (mesh)

\section{Experimental setup}

In the remainder of this paper, the joint shown in Fig. 4 will be studied through the cross-section geometry, hardness testing and high speed imaging in order to derive a set of rules concerning defects and produce a BFC.

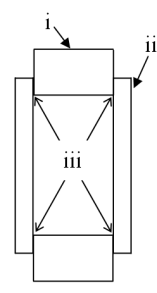

a

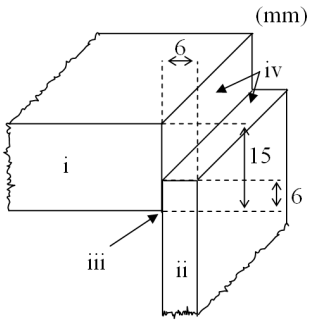

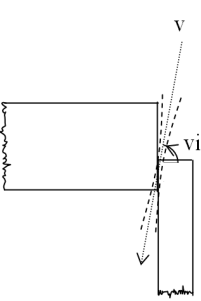

Figure 4. Workpiece joint setup. a) cross-section of the final support beam. b) joint and dimensions, c) positioning of the laser. i) Weldox 960, ii) Domex 700, iii) weld joint, iv) laser cut unprocessed surfaces with remaining oxide layer, v) path and direction of laser beam, vi) inclination angle of the laser beam.

Fig. 4a shows the cross-section (not to scale) of the final beam to be created in the LOST- project, while Fig. $4 \mathrm{~b}$ is a three dimensional image of the cross section with its dimensions. Fig. 4c shows the crosssection of the joint. Obviously, the laser beam needs to be inclined. As alignment of the beam is critical, the experiments focused on the sensitivity of altering the inclination angle, inclination position, focal depth and also the difference between flat and horizontal 
position. Horizontal welding was employed because there were fixture problems when welding the full 2 meter long support beams, which where easiest avoided by putting the plates on their sides. This also offered an opportunity to see what role gravity plays in the welds.

\section{Process parameters}

The parameters changed during the study can be seen in Tab. 3. All other parameters are fixed, as below:

- Laser: Yb:fiberlaser YLR-15000, max. power $15 \mathrm{~kW}(\mathrm{cw}), 200 \mu \mathrm{m}$ fiber, BPP $10,4 \mathrm{~mm} \cdot \mathrm{mrad}$, Wavelength: $1070 \pm 5 \mathrm{~nm}$

- Optics (collimator length / focal length): $150 / 500 \mathrm{~mm}$, (chosen because it has a long focal depth) thus magnification 3,3:1

The choice of optics and laser model yields:

- Spot diameter: $0,67 \mathrm{~mm}$.

- Rayleigh length: $\pm 8 \mathrm{~mm}$.

Laser beam arrangement:

- Laser inclination angle: $10^{\circ}$ thrusting forward

Laser power chosen:

- Laser power: $5000 \mathrm{~W}$, cw. (chosen so that it is well matched to the productivity and provides sufficient power density)

- Power density: $1,42 \times 10^{6} \mathrm{~W} / \mathrm{cm}^{2}$ (for $5000 \mathrm{~W}$, average, in the focus).

Shielding gas:

- Argon, gas flow 20 liters/min, through a nozzle near and aimed at the weld.

Material and joint:

- Domex 700 (6 mm thick) and Weldox 960 (15 $\mathrm{mm}$ thick) (both different kinds of high strength steel) are welded together in a $6 \mathrm{~mm}$ corner joint, illustrated in Fig. 4. Both plates were laser cut with oxide layer not removed.
Table.3: Variation of parameters

\begin{tabular}{|r|r|r|r|r|}
\hline No. & Weld speed & $\begin{array}{l}\text { Focal position } \\
\text { (from surface }\end{array}$ & $\begin{array}{l}\text { Inclinatior } \\
\text { angle }\end{array}$ & $\begin{array}{l}\text { lateral offset } \\
\text { (if applicable }) \\
(\mathrm{mm})\end{array}$ \\
\hline 1 & 1,0 & -1 & 5 & 0,00 \\
\hline 2 & 1,0 & -1 & 5 & 0,25 \\
\hline 3 & 1,0 & -1 & 5 & 0,50 \\
\hline 4 & 1,0 & -1 & 5 & 0,75 \\
\hline 5 & 1,25 & -1 & 5 & \\
\hline 6 & 1,5 & -1 & 5 & \\
\hline 7 & 1,75 & -1 & 5 & \\
\hline 8 & 2,0 & -1 & 5 & \\
\hline 9 & 2,25 & -1 & 5 & \\
\hline 10 & 2,5 & -1 & 5 & \\
\hline 11 & 2,5 & -1 & 10 & \\
\hline 12 & 2,0 & -1 & 10 & \\
\hline 13 & 1,5 & -1 & 10 & \\
\hline 14 & 1,5 & -2 & 10 & \\
\hline 15 & 1,5 & -3 & 10 & \\
\hline 16 & 1,5 & -4 & 10 & \\
\hline 17 & 1,5 & -5 & 10 & \\
\hline $18^{*}$ & 1,8 & -3 & 5 & 0,0 \\
\hline $19^{*}$ & 1,8 & -3 & 5 & 0,4 \\
\hline $20^{*}$ & 1,8 & -3 & 5 & 0,8 \\
\hline $21^{*}$ & 1,8 & -3 & 10 & 0,0 \\
\hline $22^{*}$ & 1,8 & -3 & 10 & 0,2 \\
\hline${ }^{*}$ Horizontal w elding position & & \\
\hline & & & & \\
\hline
\end{tabular}

\section{Results}

When examining the results of the cross-section of the welds, regions of the weld have been enhanced for clarity. Lines for the original joint and the inclination of the laser beam are also inserted into the image. By examining the resulting welds there were no visible cracks, porosity or blowouts defects detected, while lack of fusion, undercut, root sagging, reinforcement and root cavity defects were found, as discussed below.

\section{Hardness}

In Fig. 5 a Vickers hardness test made on sample No. 15 in Tab. 3 is given as an example to give a survey of how the hardness varies along the welded joint. The weld is from the left: Weldox 960 base material $\rightarrow$ Weldox 960 outer HAZ (softened material) $\rightarrow$ Weldox 960 inner HAZ (hardened coarse- grained brittle material) $\rightarrow$ weld zone $\rightarrow$ Domex 700 HAZ (softened) $\rightarrow$ Domex 700 base material. The HAZ of Weldox hardens, both sides show narrow softening, too. the weld metal often shows a linear transition in hardness. 


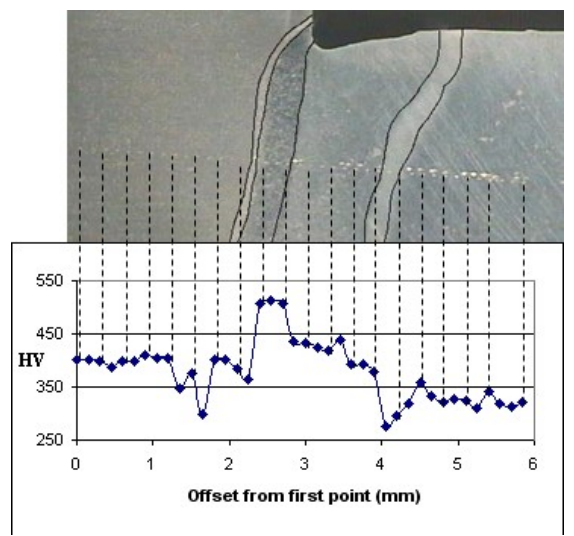

Figure 5. Vickers hardness test (left: Weldox 960, right: Domex 700)

\section{Speed variation}

A series of different welding speeds for samples No. 510 from Tab. 3 is presented in Fig. 6.
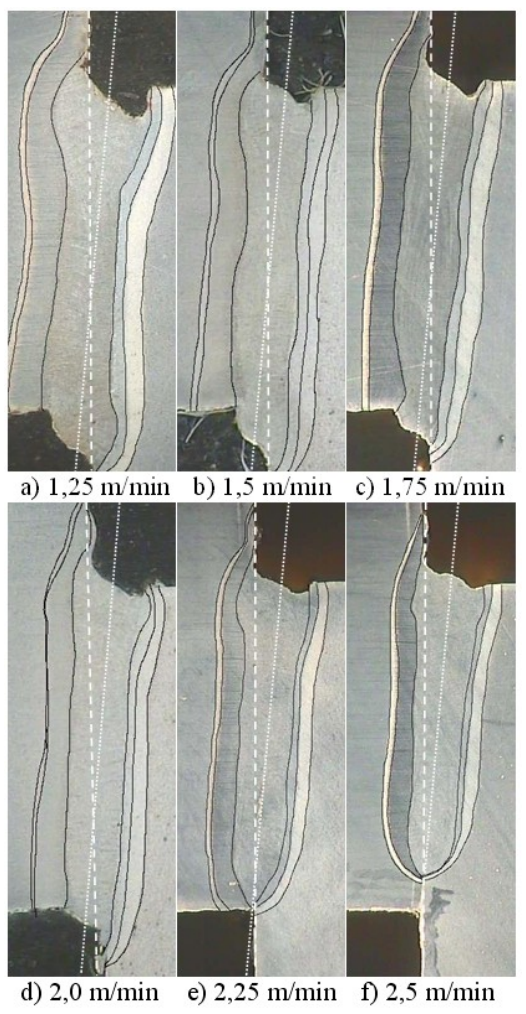

Figure 6. Change in welding speed. From a) to f) the welding speed is increased from $1,25 \mathrm{~m} / \mathrm{min}$ to $2,5 \mathrm{~m} /$ min.

When the welding speed is low, Fig. 6a, there is undercut and root sagging. When speed is increased, Figs. 6b-d, the root sagging and top undercut decreases. When welding speed is increased further, Fig. 6e, there is barely full penetration, and further in
Fig. $6 \mathrm{f}$ there is lack of fusion. In Fig. $6 \mathrm{f}$ a notch can be seen in the middle of the top surface of the weld.

In Fig. 7 the keyhole moves from right to left. When the speed is low (Fig. 7a) $1,25 \mathrm{~m} / \mathrm{min}$ a wide but short melt pool remains behind the keyhole, which gradually shrinks in width as the edges around the melt pool turn solid. When speed increases, $1,75 \mathrm{~m} / \mathrm{min}$ (Fig. $7 \mathrm{~b}$ ) and $2,25 \mathrm{~m} / \mathrm{min}$ (Fig. 7c), less heat is put into the keyhole and the sides of the melt pool turns solid faster than it does from behind (heat still remains under the surface since the weld is deep). When the speed is increased to the point where full penetration is not reached, Fig. 7d, some of the material from the keyhole flows backwards (material that otherwise would create a small root sagging) and, as a result of surface tension, makes the center of the weld pool higher than the already solidified sides of the weld pool. When this material hardens, a notch is created. Some weld pool behaviour is discussed in [13].

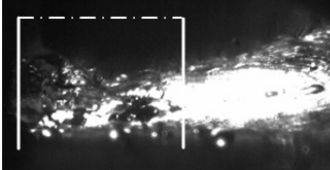

a) $1,25 \mathrm{~m} / \mathrm{min}$

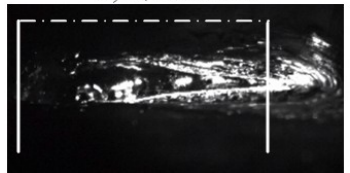

c) $2,25 \mathrm{~m} / \mathrm{min}$

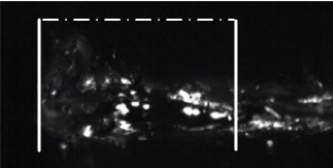

b) $1,75 \mathrm{~m} / \mathrm{min}$

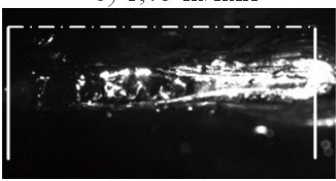

d) $2,5 \mathrm{~m} / \mathrm{min}$
Figure 7. High speed imaging snapshots at increasing welding speeds and melt pool length.

Another phenomena, that normally is hard to see, is the relation between welding speed, incomplete penetration and spatter. In Fig. 8 snapshots of spatter at different speeds can be seen. The rate of spatter generating events (melt bursts) increases with increasing speeds from approximately 10 per second at $1,25 \mathrm{~m} / \mathrm{min}$ (Fig. 8 a), to $30 \mathrm{~s}^{-1}$ at $1,75 \mathrm{~m} / \mathrm{min}$ (Fig. 8b), $150 \mathrm{~s}^{-1}$ at $2,0 \mathrm{~m} / \mathrm{min}$ (Fig. $8 \mathrm{c}$ ) and $120 \mathrm{~s}^{-1}$ at $2,5 \mathrm{~m} / \mathrm{min}$ (Fig. 8d). The level of bursts is lower for Fig. 8d than Fig. $8 \mathrm{c}$ when there is not full penetration, but the size and speed of the spatter droplets increases. 

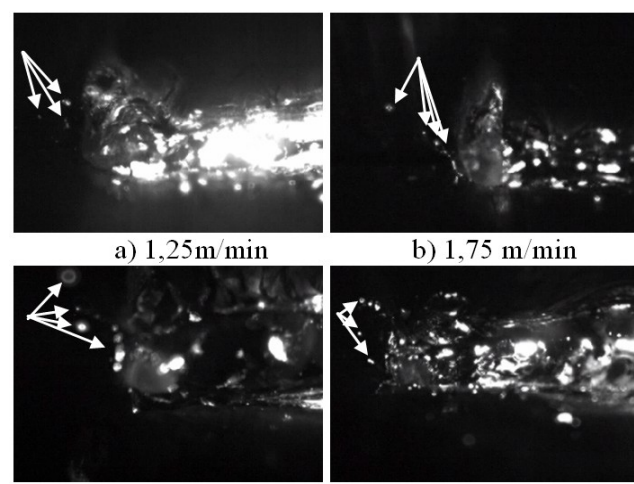

c) $2,0 \mathrm{~m} / \mathrm{min}$

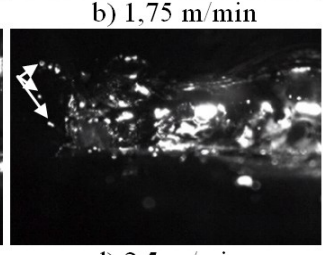

d) $2,5 \mathrm{~m} / \mathrm{min}$

Figure 8. High speed imaging snapshots showing bursts of spatter from the weld pool at increasing speeds, from a) $(1,25 \mathrm{~m} / \mathrm{min})$ to d) $(2,5 \mathrm{~m} / \mathrm{min})$.

\section{Change of alignment}

In Fig. 9 a series of cross sections is shown with increasing laser beam inclination from Figs. 9a-b (+ 0,75 mm), from sample No. 1-4 in Tab. 3. In Fig. 9a root sagging can be seen, which with each increment in inclination increases as a top undercut forms as well (Figs. 9c-d). When the laser inclination position is moved, it does not melt material on the edge and hence more energy goes into the keyhole, slowing down solidification and thus more melted material flows down the hole.

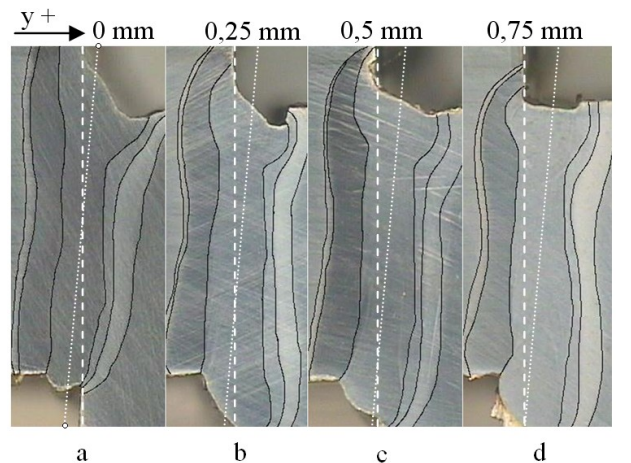

Figure 9. Cross- section of welds with $0,25 \mathrm{~mm}$ increasing laser inclination offset from a) to d).

Fig. 10 shows welds No. 18-21 from Tab. 3 (with the joint originally horizontal, but with images turned vertical for easier comparison with the standing joint images). In Fig. 10a the laser beam is too close to the corner, which shields the joint so no keyhole is created. In Fig. $10 \mathrm{~b}$ there is full penetration and no lack of fusion. In Fig. 10c the beam is too far away from the joint, resulting in lack of penetration and lack of fusion. In Fig. 10d there is full penetration and no lack of fusion, while in Fig. 10e the melt touches the left hand plate, but there is no lack of fusion of the plates until the keyhole reaches the root.

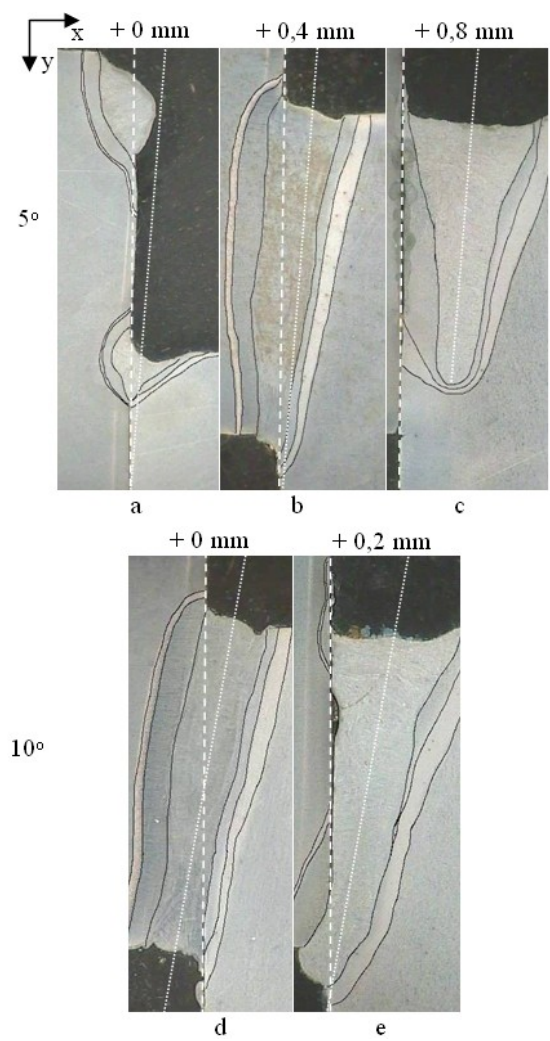

Figure 10. Cross section of lying welds with increasing distance of laser beam inclination from a) to c) with inclination angle $5^{\circ}$, and d) and e) with inclination angle $10^{\circ}$.

\section{Z-variation}

Images from No. 13-17 from Tab. 3 can be seen in Fig. 11 , where the focal position depth is lowered from -1 $\mathrm{mm}$ to $-5 \mathrm{~mm}$ (Figs. 11a-e). The width of the melted area decreases from Fig. 11a to Fig. 11c and then increases in Figs. 11d-e. When the weld width is at its thinnest there is too much energy input for the amount of melted material, causing the undercut and root sagging defects. This indicates that the weld speed can be increased. When the depth of focus is as in Figs. 11d-e the volume of melted material rises, causing reinforcement and root cavity defects. 


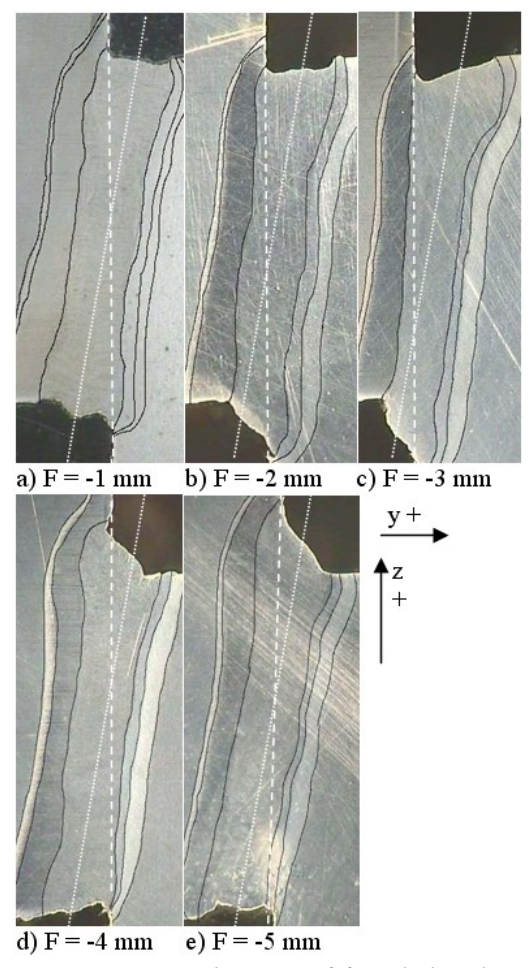

Figure 11. Change of focal depth.

\section{Angle deviation}

Figure 12 shows a comparison between $5^{\circ}$ and $10^{\circ}$ inclination angles of the laser beam at different welding speeds (corresponding to No. 6, 8, 10-12 from Tab. 3). By comparing Figs. 12a-b with Figs. 12d-e, it is revealed that the undercut and root sagging defects are largely suppressed when the inclination angle is $10^{\circ}$. In Fig. 12c there is lack of fusion, which does not occur in Fig. 12e (which in turn has a small fixture separation), resulting in full penetration, though with the undercut and root cavity defects.

A comparison between normal and horizontal joints at two different laser angles can be seen in Fig. 13 (which corresponds to weld No. 8, 12, 19 and 21 from Tab. 3). Comparing Figs. 13a-b with Figs. 13c-d respectively, it can be seen that the width of the melted area decreases at the root side when the joint is horizontal (this may be due to gravity). There is also a small decrease in top undercut when the joint is horizontal. However, the decrease in weld width at the root side increases the risk of lack of fusion, especially when the inclination angle increases from $5^{\circ}$ to $10^{\circ}$.
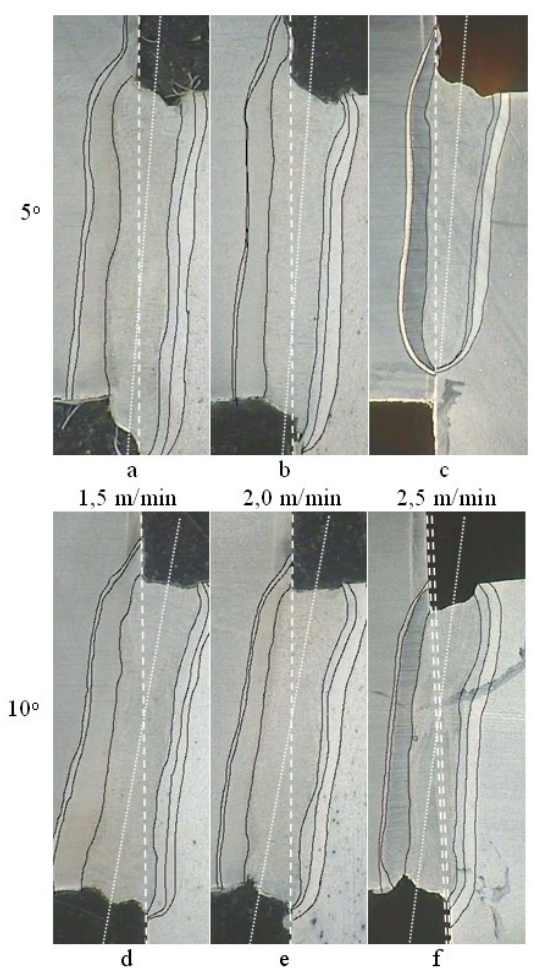

Figure 12. Inclination angle change at different speeds.

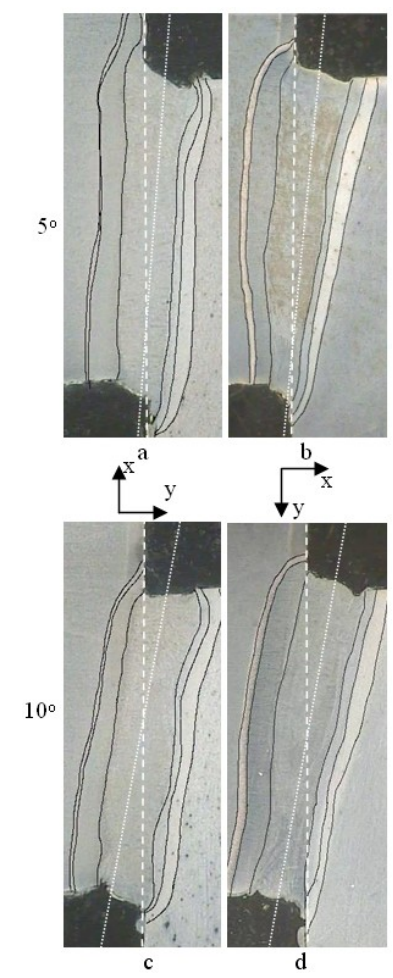

Figure 13. Different laser inclination angles with standing joint ( $a$ and $c$ ) and lying joint ( $b$ and $d$ ). 


\section{The joint as a thermal barrier}

Another issue detected during this work is the importance of the keyhole being in the joint for a full penetration with no lack of fusion. The joint itself seems to work as a thermal barrier (or insulator). Fig. 14 shows images to illustrate this, where Figs. 14a-c are cross sections of standard joints, while Figs. 14d-f are cross sections of horizontally produced welds. Heat from a keyhole (or from a point source) travels in an equal amount in each direction [14], and when a keyhole misses, but is near a joint, the heat energy between the keyhole and the joint is trapped (forced conductivity), concentrating the energy in a smaller area than the energy traveling to the other side of the keyhole (free conductivity). The joint always involves a small (or large) air gap which acts as a thermal insulator until the solid side of the joint is melted by contact with the hot melt from the other side of the joint. The air gap insulation effect can distort the final shape of the weld cross section and HAZ, as shown in figure 14.

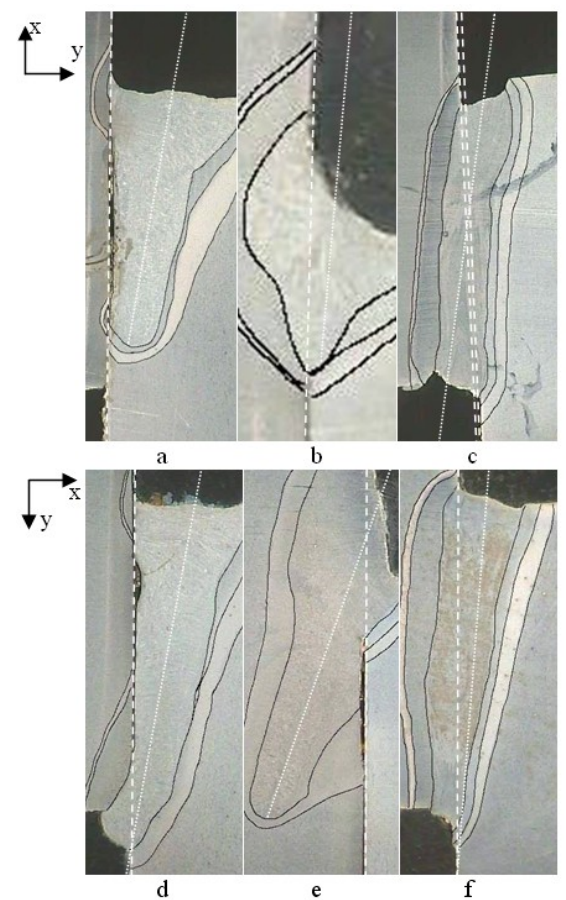

Figure 14. Images showing how the joint works as a thermal barrier.

If the direction of the keyhole and its position is correct, this joint insulation phenomenon can be utilized, making deeper welds, that can follow slight curves or irregular joint geometries. In Fig. 14b) it can be seen that the melted area reaches furthest down along the line of the original joint. When the keyhole is in the joint it can be reasoned that the photons reflects along the joint, making it easier for the keyhole to grow. But that is not the whole story, since the joint itself acts as a thermal barrier. The heat from the beam absorbed on one side of the joint stays on that side, which means that the heat created there as usual spreads equally in every direction, though near the joint it gets extremely concentrated on the side where the joint is, enabling melting of that area faster. This can actually make the keyhole take a slight turn and follow a joint, Figs. 14c,d,f. This phenomena, henceforth be called Keyhole Joint Tracking, seems to be enchanced if the presence of the joint has a small separation (Fig. 14c). It also seems that the welding speed for this phenomena is crucial (Figs. 14d-f). If the input of energy from the laser is too high, it seems that the keyhole will just follow the laser inclination direction of the laser (Fig. 14e) instead of curving along the joint.

\section{Discussion}

Even though the keyhole has a possibility to follow the joint, it is advisable not to have too high inclination angle (if the weld is deep) or too much energy in the keyhole (e.g. having too much power or running too slowly). Keyhole Joint Tracking can probably best be utilized by having a small fixture separation or having high welding speed.

By having a set of methods when analyzing welds one can deduce conclusions singularly and then start to combine them, see how the conclusions converge, thus establishing a thesis and finally a theory that can be applied in many situations, explaining either a phenomenon or the formation of specific defects. The results made in this paper can be further combined with mechanical testing, FE-Analysis and photo- diode monitoring.

Gravity seems to play a role in weld width and top undercut. When the keyhole has moved on a certain distance, the melted material fills that area, flowing down to heat up and even melt some material along the lower sides, making the melted area slightly larger. When the joint is lying on the side. In Fig. 13b, the bottom plate (on the left hand side) has a curved form, indicating that the melted material has flowed downwards, making the welded area larger on that side.

By deducing how the weld parameters change the undercut and root sagging defects, this information can be used to create a BFC as shown in Fig. 15. As mentioned earlier, the BFC can be used as a tool governed by rules. If one has a defect when welding, 
one can take a look at a BFC and see which parameter(s) can be adjusted to suppress that defect.

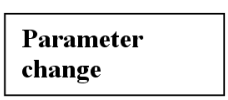

Consequence

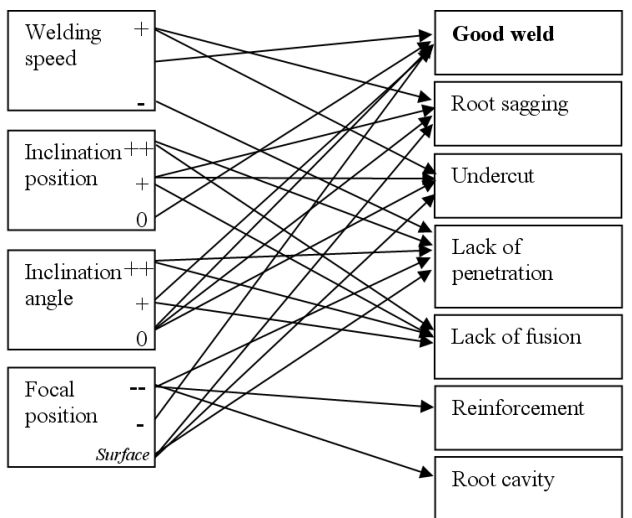

Figure 15. Bifurcation Flow Chart (BFC) showing probable impacts of parameter changes.

\section{Conclusions}

For this work the following conclusions may be drawn:

- Undercut and root sagging defects can be prevented or suppressed by

- Changing weld position from flat to horizontal

- Sufficiently large beam inclination again against sagging

- Adjusting the focal point depth (below the surface)

- Adjusting the welding speed (too slow leads to wide melt and sagging)

- Adjusting the lateral beam position (particularly sensitive when having an inclination angle)

- Spatter becomes more frequent and more intense for lack of penetration

- The weld joint interface acts as an insulator, to be thermally overcome by suitable inclination angle, position and joint separation

- The combined use of analysis methods (e.g. high speed imaging) provides more information and facilitates analysis, understanding and parameter optimisation

- Rules for suppressing defects can be stated and documented, to be proven for other cases with respect to their limits of generalisation

\section{Acknowledgements}

The authors are grateful for funding by VINNOVA The Swedish Innovation Agency for the projects LOST, HYBRIGHT and DATLAS and by the K\&A Wallenberg foundation for the fibre laser. The contributions from the Swedish companies and academic partners involved are highly appreciated.

\section{References}

[1] Kawahito, Y; Mizutani, M; and Katayama, S, (2007) Elucidation of high-power fiber laser welding phenomena of stainless steel and effect of factors on weld geometry, J. Phys. D: Appl. Phys. v 40, pp 58545859 .

[2] Shao, J; Yan, Y, (2005) Review of techniques for on-line monitoring and inspection of laser welding, J. Phys. Conference Series, 15 (1), pp. 101-107.

[3] Norman, P; Engström, H; Kaplan, A F H, (2007) State-of-the-art of Montoring and Imaging of Laser Welding Defects, in Proceedings $11^{\text {th }}$ NOLAMP Conference, Lappeenranta, Finland.

[4] Postma, S; R.G.K.M. Arts, (2002) Penetration control in laser welding of sheet metal, J. of Laser Appl. v 14, n 4, p 210-214.

[5] Fabbro, R; Slimani, S; Doudet, I; Coste, F; Briand, F, (2006) Experimental study of the dynamical coupling between the induced vapour plume and the melt pool for Nd- Yag CW laser welding, J. Phys. D: Appl. Phys. v 39, 394-400.

[6] Norman, P; Engström, H; Kaplan, A F H, (2008) Theoretical analysis of photodiode monitoring of laser welding defects by imaging combined with modelling, J. Phys D: Appl. Phys. v 41(19).

[7] Kaplan, A.F.H; Mizutani, M; Katayama, S; Matsunawa, A, (2002) Unbounded keyhole collapse and bubble formation during pulsed laser interaction with liquid zinc, J. of Phys. D: Appl. Phys. v 35, pp 1218-1228.

[8] Norman, P; Karlsson, J; Kaplan, A.F.H, (2009) Monitoring undercut, blowouts and root sagging during laser beam welding, in Proceedings of the Fifth WLT-Conference on Lasers Manufacturing, Munich, Germany

[9] Karlsson, J; Ilar, T; Kaplan, A.F.H, (2009) Knowledge platform approach for fiberlaser welding 
of high strength steel, in Proceedings $12^{\text {th }}$ NOLAMP conference, Copenhagen, Denmark (inPress)

[10] Kaplan, A.F.H; (2008) Advanced systematic theory of laser welding supported by high speed imaging, Proc. GCL, 2008, Lisbon (PT), SPIE.

[11] -, Swedish standard, SS-EN ISO 13919-1, p. 27 (1996)

[12] Alam, M; Kaplan, A.F.H, (2009) The effects of surface topography and lack of fusion on the fatigue strength of laser hybrid welds, in Proceedings ICALEO conference, Orlando, Florida, USA (inPress)

[13] Kaplan, A, (2009) Keyhole Welding: The Solid and Liquid Phases, in The Theory of Laser Materials Processing, Springer Series in Materials Science, 7193.

[14] Kroos, J; Gratzke, U; Simon, G, (1993) Towards a self-consistent model of the keyhole in penetration laser beam welding, J. of Phys. D: Appl. Phys. v 26, 474-480.

\section{Meet the authors}

Jan Karlsson was born in Umeå, Sweden in 1982. He received a B.Sc in Computer Engineering 2007 and a M.Sc in Physics 2008 from Luleå University of Technology (LTU), Sweden. He has been working at the division of Manufacturing Systems Engineering at LTU since. He researches laser welding and his focus is to simplify and concretize laser welding.

Alexander Kaplan was born in Vienna, Austria in 1967, employed as researcher at Vienna TU from 1989 until 2000, receiving a $\mathrm{PhD}$ in 1994 on laser welding modelling. After a post-doc year at Osaka University, Japan, from 2002 on he is appointed as professor and head of division on manufacturing at Luleå University of Technology, Sweden. His research focus comprises laser materials processing, in particular process modelling, laser welding and hybrid welding. Contact: alexander.kaplan@ltu.se 